•综述・

\title{
中国熊蜂多样性、人工利用与保护策略
}

\author{
黄家兴 安建东 \\ (中国农业科学院蜜蜂研究所, 农业部授粉昆虫生物学重点实验室, 北京 100093)
}

\begin{abstract}
摘要: 熊蜂是众多野生植物和农作物的重要传粉者, 在维持自然和农业生态系统平衡中发挥着十分重要的作用。 中国地形多样、植被丰富, 是全球熊蜂多样性的热点地区, 但过去缺乏系统调查研究, 中国熊蜂多样性现状及其利 用特性不详。本文介绍了近20年在中国熊蜂资源系统调查及其人工利用方面取得的主要研究结果: (1) 2002-2017 年采集熊蜂标本 5 万余号, 先后揭示了一系列疑难类群的分类地位, 确认中国已知熊蜂 125 种, 占全球熊蜂已知物 种总数的 $50 \%$, 表明中国是全球熊蜂物种资源最丰富的国家; (2)首次报道了中国熊蜂物种名录, 其中 22 种为中国 特有种。我国青藏高原东部向黄土高原、秦岭山地和四川盆地过渡的地带, 是全球熊蜂多样性分布中心; (3) 1998-2017年, 明亮熊蜂(Bombus lucorum)、密林熊蜂(B. patagiatus)、红光熊蜂(B. ignitus)、火红熊蜂(B. pyrosoma)、 重黄熊蜂(B. picipes)和兰州熊蜂(B. lantschouensis) 6种本土熊蜂先后被驯养成功, 其中密林熊蜂和兰州熊蜂的繁殖 性状优良，已应用于我国设施作物传粉服务。同时，我们从栖息地、食物资源、外来物种、农药使用等方面提出 了保护中国熊蜂资源的策略, 以期为野生传粉昆虫特别是熊蜂资源的保护与可持续利用提供参考资料。
\end{abstract}

关键词：传粉者; 熊蜂; 野外调查; 繁育篮选; 传粉; 保护

\section{Species diversity, pollination application and strategy for conservation of the bumblebees of China}

\author{
Jiaxing Huang, Jiandong $\mathrm{An}^{*}$ \\ Institute of Apicultural Research, Chinese Academy of Agricultural Sciences, Key Laboratory for Insect-Pollinator Biol- \\ ogy of the Ministry of Agriculture, Beijing 100093
}

\begin{abstract}
Bumblebees are important pollinators of many wild flowers and crops and play a significant role in maintaining natural and agricultural ecosystems. The varied geomorphology and vegetation of China makes it the greatest hotspot of bumblebee diversity in the world. However, the bumblebee fauna of China has been insufficiently studied. Here, we report the results of systematic field surveys and the application of bumblebees to pollination over the last two decades in China. The results showed the following: (1) More than 50,000 bumblebee specimens were collected during 2002-2017. The taxonomic status of some difficult taxa was revealed by integrating morphology with DNA barcoding. A total of 125 bumblebee species have been identified, which represents $50 \%$ of the total number of bumblebee species worldwide. (2) We report the first compiled list of the bumblebee species of China, which includes 22 species that are endemic to China. The transitional zone from the eastern Qinghai-Tibetan Plateau to the Loess Plateau, the Qinling Mountains, and the Sichuan Basin is the centre of bumblebee diversity worldwide. (3) Six native bumblebee species, including Bombus lucorum, B. patagiatus, B. ignitus, B. pyrosoma, B. picipes and B. lantschouensis from Northern China, were selected for rearing between 1998-2017. Furthermore, B. patagiatus and B. lantschouensis, which had traits that favoured domestication, are now used as pollinators of crops in greenhouses within China. We propose a multi-pronged strategy to conserve the native bumblebees of China, which includes protecting their habitats and food resources and controlling invasive alien species and pesticide use. We hope that this study will help inform the conservation and the sustainable use of wild pollinators across the globe, but especially bumblebees of China.
\end{abstract}

Key words: pollinator; bumblebee; field survey; rearing selection; pollination; conservation

收稿日期: 2018-03-05; 接受日期: 2018-04-10

基金项目: 国家自然科学基金(30672500, U1603108)和中国农业科学院科技创新工程(CAAS-ASTIP-2015-IAR)

* 通讯作者 Author for correspondence. E-mail: anjiandong@caas.cn 
熊蜂是众多野生植物和农作物的重要传粉者, 在维持自然和农业生态系统平衡中发挥着十分重 要的作用。熊蜂隶属于膜翅目蜜蜂科熊蜂属 (Bombus), 由15个亚属组成(Williams et al, 2008)。除 大洋洲区、古热带区没有自然分布外, 熊蜂广泛分 布于东洋区、古北区、新北区和新热带区, 甚至在 北极圈以南 $88 \mathrm{~km}$ 的地方也有分布, 其中北半球温 带和寒温带地区熊蜂分布较丰富(Heinrich, 1979; Williams，1996)。目前，全球已知熊蜂约 250 种 (Cameron et al, 2007)。中国地形多样, 植被丰富, 是 全球熊蜂物种资源最丰富的国家(Williams，1998; Williams et al, 2009)。

相比于欧洲, 中国对熊蜂的区系研究较晚, 而 且过去一直缺乏系统的野外调查。20世纪70年代以 前, 有关中国熊蜂的描述主要来自美国、瑞典和德 国等西方学者的调查报告。例如, 20世纪20-40年代, 美国博物学家David Crockett Graham博士在四川宜 宾采到7种熊蜂(谢正华, 2008); 1927-1930年, 在 Sven Hedin博士和Sü Ping-chang教授率领下, 瑞典中国科学考察队在中国西北地区进行了一次综合 性生物资源考察, 他们结合德国柏林博物馆等馆藏 记录, 报道了中国熊蜂属 11 亚属 38 种 (Bischoff, 1936)。俄罗斯科学家Д. В. Панфилов在前人的基础 上, 分析了中国4个亚区(日本-中国-喜马拉雅山亚 区、西藏高原亚区、哈萨克斯坦-蒙古亚区、西伯 利亚亚区)的熊蜂分布特点, 并预言中国是全球熊 蜂资源最丰富的国家(潘菲洛夫, 1957)。但是这些报 道中大部分熊蜂物种都缺少详细的分布信息。20世 纪70年代以来, 中国科学院开展了一系列大型科学 考察活动, 采到较多的熊蜂标本。随后, 中国科学 院动物研究所等单位的专家相继报道了中国部分 地区的熊蜂物种名录, 例如, 西藏地区有42种(王淑 芳, 1982), 新疆天山托尔峰地区21种(王淑芳, 1985), 云南27种(吴燕如等, 1988), 长江三峡库区16种(姚 建和罗春勇, 1997), 浙江15种(於文俊等, 2003; 姚 建和王淑芳, 2005), 秦岭西段33种(姚建和王淑芳, 2005)。另报道, 台湾省有熊蜂9种(Starr, 1992), 川 渝地区有56种(谢正华, 2008; Williams et al, 2009)。 但是, 中国整体熊蜂物种资源及其分布特征不详。 此外，中国地处东洋区向古北区过渡的地带，境内 熊蜂体色模式多样, 疑难类群较多, 造成很多物种 分类地位有误(An et al, 2014)。20世纪90年代末，中
国农业科学院蜜蜂研究所牵头开展了中国熊蜂资 源本底调查，同时探索特殊种群人工驯养和传粉利 用的可行性。

本文介绍了近 20 年来中国熊蜂资源调查及其 人工开发利用的研究进展, 并提出了中国熊蜂资源 的保护策略。

\section{中国熊蜂资源本底调查}

随着设施农业和熊蜂商品化的发展，全球范围 内掀起了设施果菜应用熊蜂传粉的热潮(Velthuis \& van Doorn, 2006)。中国于1995年正式立项研究熊蜂 的利用技术，1998年本土熊蜂人工繁殖获得成功， 随后开始应用于设施果菜传粉(梁诗魁等, 1999)。但 在应用过程中, 发现我国本土熊蜂资源现状不清, 很多物种鉴定困难，一些熊蜂物种甚至出现几易其 名的情况, 给相关研究和利用带来了诸多困惑(安 建东等, 2007, 2010; Williams et al, 2012a)。因此，由 中国农业科学院蜜蜂研究所牵头, 山西省农业科学 院园艺研究所、甘肃省养蜂研究所、新疆农垦科学 院、新疆维吾尔自治区蜂业发展中心、宁夏固原市 养蜂试验站、陕西榆林市蜂业技术推广站、榆林市 草原工作站、西藏自治区农牧科学院、西藏农牧学 院、广东省昆虫研究所、云南省农业科学院蚕桑蜜 蜂研究所、安徽黄山种蜂场、重庆市畜牧科学院、 福建农林大学、黑龙江省农业科学院牡丹江分院、 辽宁省蜜蜂原种场、山东省农业科学院植物保护研 究所、河南科技学院、江西省养蜂研究所、浙江金 华市农业科学研究院、广西农林蜜蜂开发研究所和 海南省农业学校等协作单位参加, 在全国范围内开 展了中国熊蜂资源本底系统调查。2002-2017年，协 作组完成了中国大部分地区的野外调查，共采集熊 蜂标本5万余号, 涉及 1,780 个采样点(图1)。同时, 采 用传统形态特征和DNA条形码相结合的分类手段, 先后揭示了小峰熊蜂隐存种(Bombus hypocrita cryptic species) (Williams et al, 2012a)、明亮熊蜂复 合种(B. lucorum complex) (刘苹等, 2014)、三条熊蜂 复合种(B. trifasciatus complex) (Huang et al, 2015a)、朝鲜熊蜂体色模式多态性(B. koreanus colour-pattern polymorphism) (Huang et al, 2015b)等 一系列疑难类群的分类地位, 探明了地熊蜂亚属 (Subterraneobombus) (Williams et al, 2011)、熊蜂亚 属(Bombus) (Williams et al, 2012b)、巨熊蜂亚属 


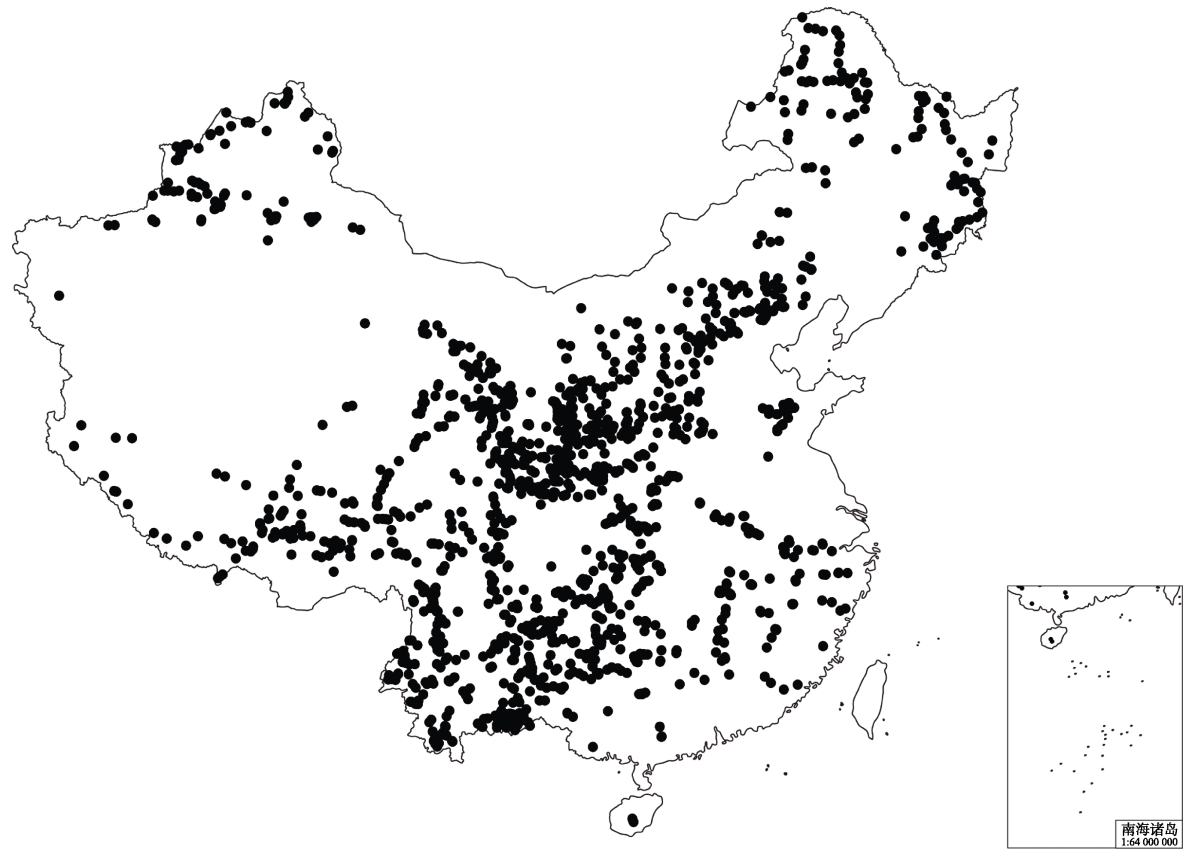

图1 中国境内熊蜂分布点(基于中国农业科学院蜜蜂研究所2002-2017年采集的标本数据)

Fig. 1 Map of China showing the distribution sites of the bumblebees of China used the records of the collection of Institute of Apicultural Research of Chinese Academy of Agricultural Sciences between 2002-2017.

(Megabombus) (Huang et al, 2015a)、假熊蜂亚属 (Mendacibombus) (Williams et al, 2016)等类群的物 种组成及其系统发育关系, 明确了中国北方(安建 东等, 2008, 2010; An et al, 2011, 2014)和青藏高原 (Williams et al, 2015)等地区的熊蜂物种多样性现 状。截至目前, 已确认分布在中国的熊蜂有125种 (表1), 占全球已知熊蜂物种总数的 $50 \%$, 表明中国 是全球熊蜂物种资源最丰富的国家。另外, 还有一 些未知种尚在鉴定之中。预计, 中国熊蜂物种总数 将会超过130种(Williams et al, 2017)。

\section{2 中国熊蜂物种多样性现状}

\section{1 物种名录}

目前, 中国已知熊蜂125种, 隶属于14亚属, 物 种数量由多到少依次为胸熊蜂亚属(Thoracobombus) 20种, 火熊蜂亚属(Pyrobombus) 19种, 拟熊蜂亚属 (Psithyrus) 18种, 巨熊蜂亚属(Megabombus) 16种, 黑熊蜂亚属 (Melanobombus) 11 种, 熊蜂亚属 (Bombus) 10种, 假熊蜂亚属(Mendacibombus)、地熊 蜂亚属(Subterraneobombus) 和阿熊蜂亚属 (Alpigenobombus)各7种, 西熊蜂亚属(Sibiricobombus) 4种, 东熊蜂亚属(Orientalibombus) 3种, 巴熊蜂亚属 (Bombias)、凯熊蜂亚属(Kallobombus)和卡熊蜂亚属
(Cullumanobombus)各1种。125种熊蜂中, 火红熊蜂 (Bombus pyrosoma)、凸污熊蜂(B. convexus)、壮熊 蜂(B. validus)、长足熊蜂(B. longipes)、重黄熊蜂(B. picipes)、三条熊蜂(B. trifasciatus)、仿熊蜂(B. imitator)、中华熊蜂(B. chinensis)等22种为中国特有种 (表1)。除分布于台湾的单带熊蜂(B. monozonus)、 楚南熊蜂(B. sonani)和短项熊蜂(B. angustus) 3 种外 (Starr, 1992), 其余122种熊蜂(5万余号)的凭证标本 均保存于中国农业科学院蜜蜂研究所。

\section{2 物种丰富度}

中国陆地面积约等于美国和欧洲, 但熊蜂物种 数量约为美国的3倍、欧洲的1.5倍(Williams et al, 2010，2014), 是全球熊蜂物种资源最丰富的国家。 调查结果显示, 除了新疆的塔克拉玛干沙漠和古尔 班通古特沙漠以及内蒙古的巴丹吉林沙漠外, 熊蜂 在我国大部分地区都有分布(图1)。经纬度 $3^{\circ} \times 3^{\circ}$ 方 格内的物种丰富度分析显示, 中国北方温带地区熊 蜂物种比较丰富, 南方热带亚热带地区物种较少; 青藏高原东部边缘向黄土高原、秦岭山地及四川盆 地过渡的地带是中国熊蜂物种资源最丰富的地区, 其中西秦岭及其周边山地物种数量最高(达45 种)(图2), 这一地区也是全球熊蜂的多样性分布中 心(Williams, 1998; Williams et al, 2009)。中国农业 
表1 中国熊蜂属物种名录(*中国特有种)

Table 1 List of the bumblebee species of the genus Bombus in China. * Species endemic to China.

\begin{tabular}{|c|c|}
\hline 物种 Species & 物种 Species \\
\hline 短规熊蜂 Bombus (Alpigenobombus) angustus * & 红束熊蜂 Bombus (Melanobombus) rufofasciatus \\
\hline 短头熊蜂 Bombus (Alpigenobombus) breviceps & 西氏熊蜂 Bombus (Melanobombus) sichelii \\
\hline 项熊蜂 Bombus (Alpigenobombus) genalis & 莺熊蜂 Bombus (Melanobombus) tanguticus \\
\hline 灰熊蜂 Bombus (Alpigenobombus) grahami & 凸污熊蜂 Bombus (Mendacibombus) convexus ${ }^{*}$ \\
\hline 克什米尔熊蜂 Bombus (Alpigenobombus) kashmirensis & 松熊蜂 Bombus (Mendacibombus) defector \\
\hline 显熊蜂 Bombus (Alpigenobombus) nobilis & 马卡熊蜂 Bombus (Mendacibombus) makarjini \\
\hline 壮熊蜂 Bombus (Alpigenobombus) validus * & 马格熊蜂 Bombus (Mendacibombus) margreiteri \\
\hline 混熊蜂 Bombus (Bombias) confusus & 华丽熊蜂 Bombus (Mendacibombus) superbus ${ }^{*}$ \\
\hline 隐熊蜂 Bombus (Bombus) cryptarum & 土耳其熊蜂 Bombus (Mendacibombus) turkestanicus \\
\hline 小峰熊蜂 Bombus (Bombus) hypocrita & 稳纹熊蜂 Bombus (Mendacibombus) waltoni \\
\hline 红光熊蜂 Bombus (Bombus) ignitus & 娇熊蜂 Bombus (Orientalibombus) braccatus * \\
\hline 兰州熊蜂 Bombus (Bombus) lantschouensis & 埋熊蜂 Bombus (Orientalibombus) funerarius \\
\hline 长翅熊蜂 Bombus (Bombus) longipennis & 红尾熊蜂 Bombus (Orientalibombus) haemorrhoidalis \\
\hline 明亮熊蜂 Bombus (Bombus) lucorum & 巴氏熊蜂 Bombus (Psithyrus) barbutellus \\
\hline 岷山熊蜂 Bombus (Bombus) minshanensis * & 贝拉熊蜂 Bombus (Psithyrus) bellardii \\
\hline 密林熊蜂 Bombus (Bombus) patagiatus & 牛熊蜂 Bombus (Psithyrus) bohemicus \\
\hline 散熊蜂 Bombus (Bombus) sporadicus & 布氏熊蜂 Bombus (Psithyrus) branickii \\
\hline 地熊蜂 Bombus (Bombus) terrestris & 田野熊蜂 Bombus (Psithyrus) campestris \\
\hline 卡氏熊蜂 Bombus (Cullumanobombus) cullumanus & 中华熊蜂 Bombus (Psithyrus) chinensis * \\
\hline 索熊蜂 Bombus (Kallobombus) soroeensis & 韩熊蜂 Bombus (Psithyrus) coreanus \\
\hline 侧白熊蜂 Bombus (Megabombus) albopleuralis & 角熊蜂 Bombus (Psithyrus) cornutus \\
\hline 双色熊蜂 Bombus (Megabombus) bicoloratus & 埃熊蜂 Bombus (Psithyrus) expolitus ${ }^{*}$ \\
\hline 亲熊蜂 Bombus (Megabombus) consobrinus & 费熊蜂 Bombus (Psithyrus) ferganicus \\
\hline 茨氏熊蜂 Bombus (Megabombus) czerskii & 单带熊蜂 Bombus (Psithyrus) monozonus ${ }^{*}$ \\
\hline 长规熊蜂 Bombus (Megabombus) hortorum & 莫氏熊蜂 Bombus (Psithyrus) morawitzianus \\
\hline 朝鲜熊蜂 Bombus (Megabombus) koreanus & 挪威熊蜂 Bombus (Psithyrus) norvegicus \\
\hline 长足熊蜂 Bombus (Megabombus) longipes * & 崖熊蜂 Bombus (Psithyrus) rupestris \\
\hline 玛氏熊蜂 Bombus (Megabombus) malaisei & 斯科熊蜂 Bombus (Psithyrus) skorikovi \\
\hline 山岭熊蜂 Bombus (Megabombus) montivagus & 寓林熊蜂 Bombus (Psithyrus) sylvestris \\
\hline 圣熊蜂 Bombus (Megabombus) religiosus ${ }^{*}$ & 西藏熊蜂 Bombus (Psithyrus) tibetanus ${ }^{*}$ \\
\hline 安熊蜂 Bombus (Megabombus) securus * & 图氏熊蜂 Bombus (Psithyrus) turneri \\
\hline 越熊蜂 Bombus (Megabombus) supremus * & 常熊蜂 Bombus (Pyrobombus) avanus \\
\hline 苏氏熊蜂 Bombus (Megabombus) sushkini s. 1. & 毕氏熊蜂 Bombus (Pyrobombus) biroi \\
\hline 遆氏熊蜂 Bombus (Megabombus) tichenkoi s. l. & 黄熊蜂 Bombus (Pyrobombus) flavescens \\
\hline 三条熊蜂 Bombus (Megabombus) trifasciatus * & 眠熊蜂 Bombus (Pyrobombus) hypnorum \\
\hline 乌苏里熊蜂 Bombus (Megabombus) ussurensis & 稀熊蜂 Bombus (Pyrobombus) infrequens \\
\hline 萃熊蜂 Bombus (Melanobombus) eximius & 柔熊蜂 Bombus (Pyrobombus) infirmus ${ }^{*}$ \\
\hline 白背熊蜂 Bombus (Melanobombus) festivus & 拉普熊蜂 Bombus (Pyrobombus) lapponicus \\
\hline 弗里熊蜂 Bombus (Melanobombus) friseanus & 饰带熊蜂 Bombus (Pyrobombus) lemniscatus \\
\hline 昆仑熊蜂 Bombus (Melanobombus) keriensis & 小雅熊蜂 Bombus (Pyrobombus) lepidus \\
\hline 拉达克熊蜂 Bombus (Melanobombus) ladakhensis & 黄足熊蜂 Bombus (Pyrobombus) luteipes \\
\hline 银珠熊蜂 Bombus (Melanobombus) miniatus & 谦熊蜂 Bombus (Pyrobombus) modestus \\
\hline 火红熊蜂 Bombus (Melanobombus) pyrosoma * & 洁熊蜂 Bombus (Pyrobombus) parthenius s. l. \\
\hline 雀熊蜂 Bombus (Melanobombus) richardsiellus & 重黄熊蜂 Bombus (Pyrobombus) picipes * \\
\hline
\end{tabular}


表1 (续) Table 1 (continued)

\begin{tabular}{|c|c|}
\hline 物种 Species & 物种 Species \\
\hline 早熊蜂 Bombus (Pyrobombus) pratorum & 黑足熊蜂 Bombus (Thoracobombus) atripes \\
\hline 缢熊蜂 Bombus (Pyrobombus) pressus & 德熊蜂 Bombus (Thoracobombus) deuteronymus \\
\hline 圆头熊蜂 Bombus (Pyrobombus) rotundiceps & 纤熊蜂 Bombus (Thoracobombus) exil \\
\hline 楚南熊蜂 Bombus (Pyrobombus) sonani * & 盗熊蜂 Bombus (Thoracobombus) filchnerae \\
\hline 白尾熊蜂 Bombus (Pyrobombus) subtypicus & 锈红熊蜂 Bombus (Thoracobombus) hedini \\
\hline 王氏熊蜂 Bombus (Pyrobombus) wangae * & 褐纹熊蜂 Bombus (Thoracobombus) humilis \\
\hline 亚洲熊蜂 Bombus (Sibiricobombus) asiaticus & 仿熊蜂 Bombus (Thoracobombus) imitator ${ }^{*}$ \\
\hline 默氏熊蜂 Bombus (Sibiricobombus) morawitzi & 兴熊蜂 Bombus (Thoracobombus) impetuosus \\
\hline 谢氏熊蜂 Bombus (Sibiricobombus) semenovi & 拉熊蜂 Bombus (Thoracobombus) laesus \\
\hline 西伯熊蜂 Bombus (Sibiricobombus) sibiricus & 藓状熊蜂 Bombus (Thoracobombus) muscorum \\
\hline 阿穆尔熊蜂 Bombus (Subterraneobombus) amurensis & 富丽熊蜂 Bombus (Thoracobombus) opulentus \\
\hline 猛熊蜂 Bombus (Subterraneobombus) difficillimus & 牧场熊蜂 Bombus (Thoracobombus) pascuorum \\
\hline 卓熊蜂 Bombus (Subterraneobombus) distinguendus & 拟贝熊蜂 Bombus (Thoracobombus) pseudobaicalensis \\
\hline 芳香熊蜂 Bombus (Subterraneobombus) fragrans & 疏熊蜂 Bombus (Thoracobombus) remotus * \\
\hline 黑尾熊蜂 Bombus (Subterraneobombus) melanurus & 红柄熊蜂 Bombus (Thoracobombus) ruderarius \\
\hline 伪猛熊蜂 Bombus (Subterraneobombus) personatus & 斯氏熊蜂 Bombus (Thoracobombus) schrencki \\
\hline 短毛熊蜂 Bombus (Subterraneobombus) subterraneus & 三角熊蜂 Bombus (Thoracobombus) tricornis \\
\hline 舞熊蜂 Bombus (Thoracobombus) anachoreta & 长头熊蜂 Bombus (Thoracobombus) veteranus \\
\hline 杏色熊蜂 Bombus (Thoracobombus) armeniacus & \\
\hline
\end{tabular}

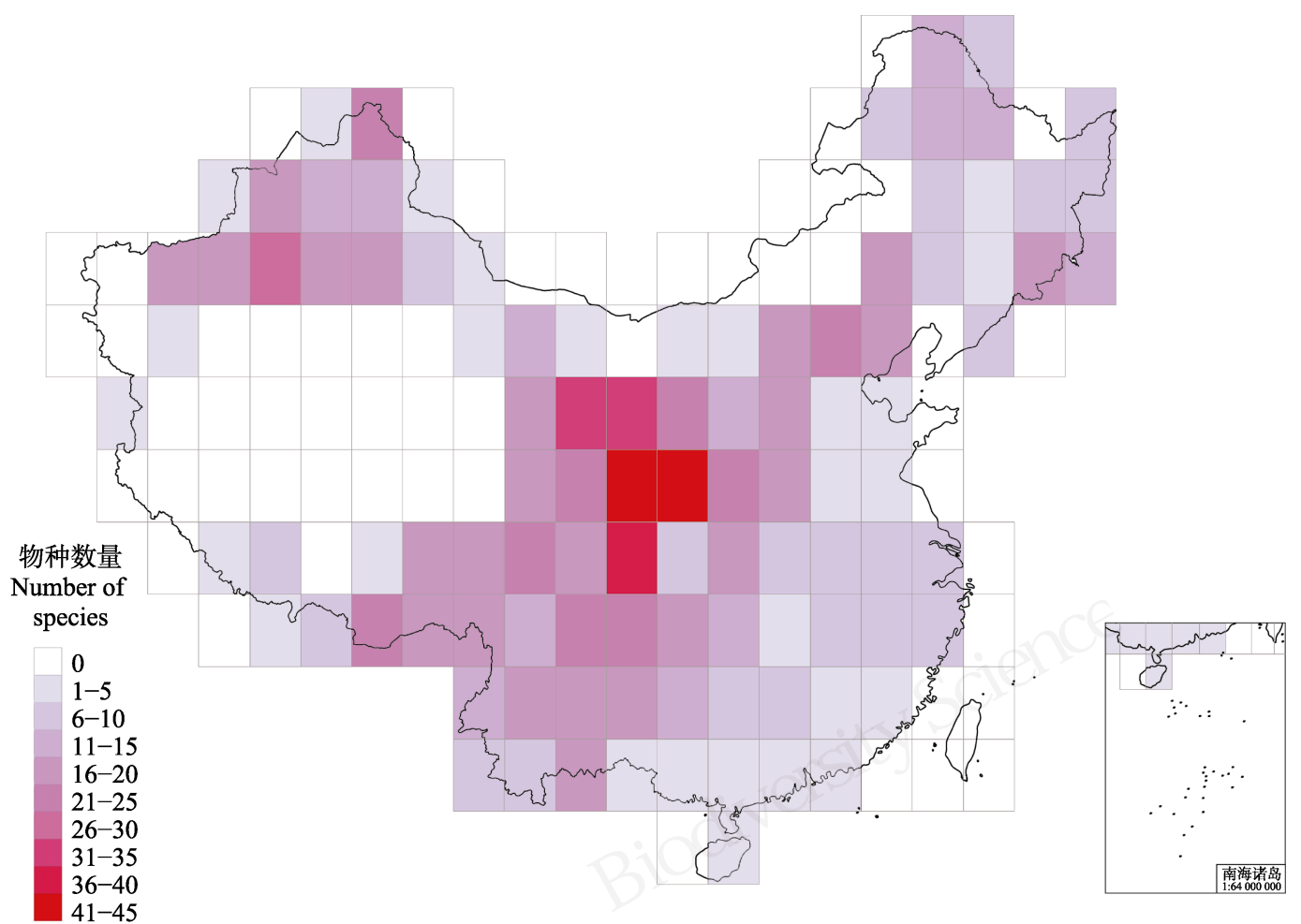

图2 中国境内熊蜂物种丰富度变化(基于经纬度 $3^{\circ} \times 3^{\circ}$ 方格内的物种数量分析)

Fig. 2 Map of China showing variation in bumblebee species richness across China measured as the number of species recorded within each grid cell of $3^{\circ}$ longitude $\times 3^{\circ}$ latitude. 

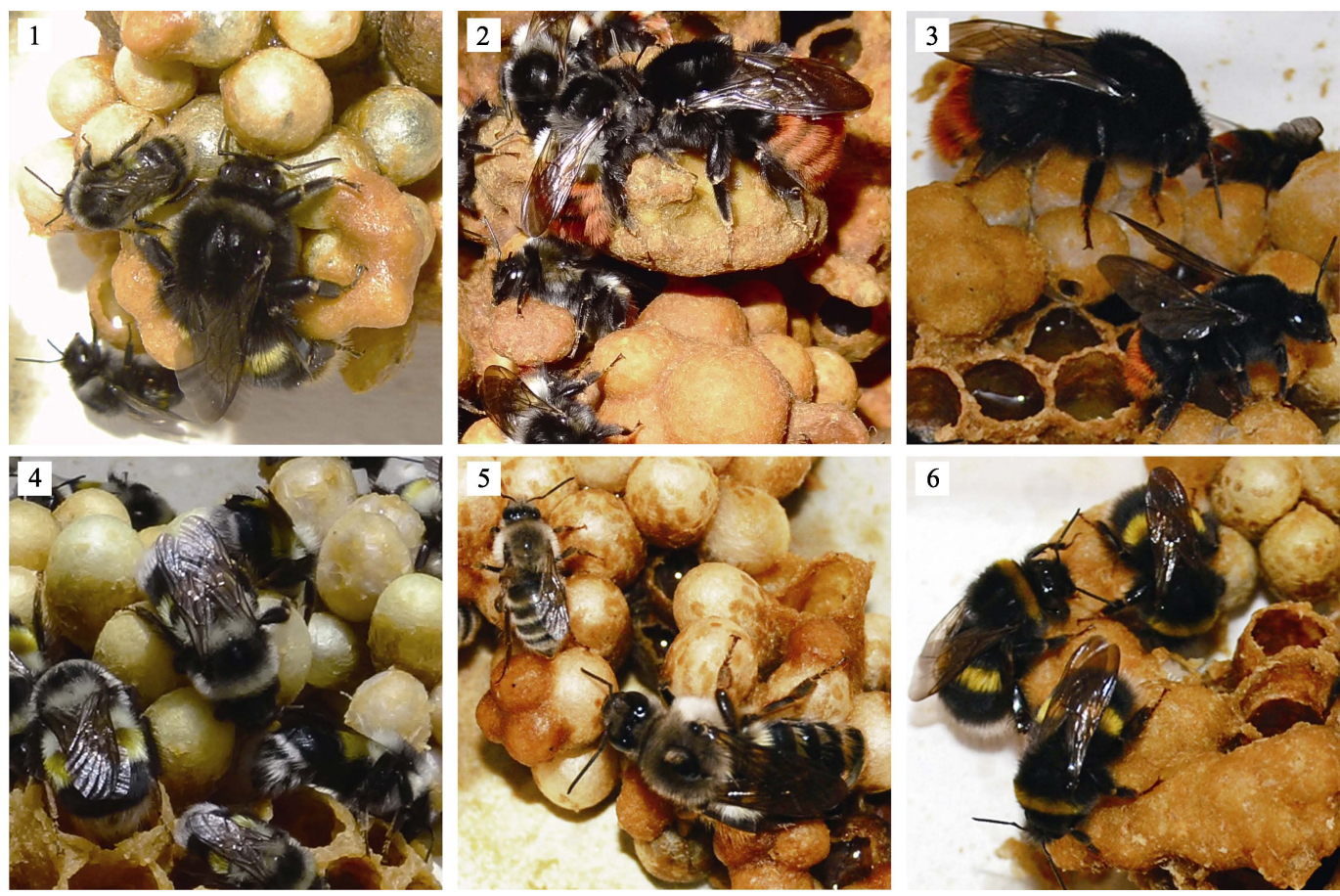

图3 通过人工饲养笁选出来的6种中国本土熊蜂。(1)密林熊蜂; (2)火红熊蜂; (3)红光熊蜂; (4)兰州熊蜂; (5)重黄熊蜂; (6)明亮 熊蜂。

Fig. 3 Six Chinese bumblebee species that have been selected for rearing and pollination. Bumblebee colonies include: (1) Bombus patagiatus, (2) B. pyrosoma, (3) B. ignitus, (4) B. lantschouensis, (5) B. picipes, (6) B. lucorum.

科学院蜜蜂研究所馆藏记录显示，甘肃和四川各分 布有熊蜂57种，是我国熊蜂物种资源最丰富的省区; 在中国境内, 从海拔 $9 \mathrm{~m}$ 的东南沿海到海拔 $5,200 \mathrm{~m}$ 的青藏高原都有熊蜂分布，但 $50 \%$ 以上分布点的海 拔在900-2,500 m之间。

\section{3 中国熊蜂人工利用现状}

\section{1 人工節选}

熊蜂具有独特的生物学特性, 是设施作物尤其 是茄果类作物理想的传粉昆虫。但是熊蜂人工饲养 难度大，目前只有荷兰、以色列、美国等少数国家 真正掌握熊蜂的规模化繁育技术。1998年, 中国农 业科学院蜜蜂研究所首次获得本土明亮熊蜂 (Bombus lucorum)人工繁殖的成功, 随后, 密林熊 蜂(B. patagiatus)、红光熊蜂(B. ignitus)、火红熊蜂、 重黄熊蜂和兰州熊蜂(B. lantschouensis)等蜂种被相 继笁选出来(图3), 这6种熊蜂易于人工饲养, 具有 较好的利用前景(梁诗魁等, 1999; 安建东等, 2010)。其中, 兰州熊蜂和密林熊蜂人工饲养时成群 率在70\%以上，而且蜂群群势大，工蜂可达200余只， 子代蜂王数量多且交配成功率高, 这2种熊蜂繁殖
性状优良，是有望实现规模化生产和传粉应用的重 要种质资源 ${ }^{\circledR}$ 。

虽然我国䇥选出来的密林熊蜂和兰州熊蜂已 被用于设施作物传粉(图4), 但其成群率、工蜂数量、 蜂王交尾成功率等繁殖性状和欧洲地熊蜂(Bombus terrstris)相比仍存在较大的差距 ${ }^{1}$ 。而且, 熊蜂的人

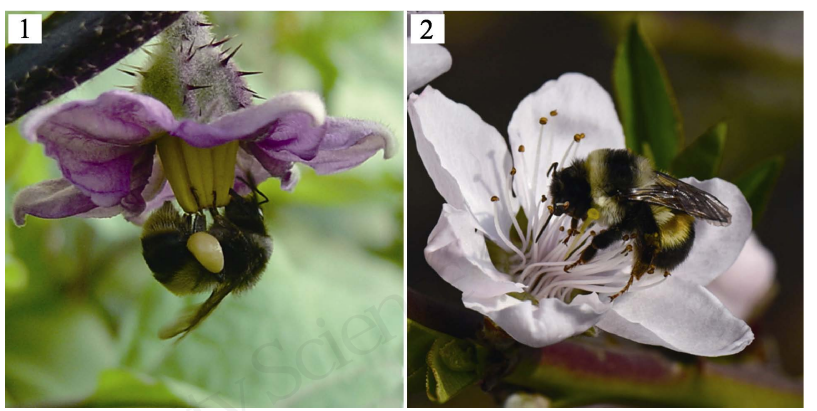

图4 密林熊蜂和兰州熊蜂2种中国本土熊蜂已用于设施作 物传粉服务。(1)显示密林熊蜂工蜂访问茄花, (2)显示兰州熊 蜂工蜂访问桃花。

Fig. 4 Two Chinese bumblebee species have been used for pollination of crops in greenhouses. (1) shows a worker of Bombus patagiatus visiting an eggplant flower, and (2) shows a worker of $B$. lantschouensis visiting a peach flower.

(1) 周志勇 (2016) 中国四种熊蜂的生物学特性比较. 硕士学位论文, 中 国农业科学院, 北京. 
工繁育是一个非常复杂的系统工程, 涉及营养、机 具、工艺流程、环境控制、生殖调控、蜂王冷藏、 后代复壮等一系列技术环节(盖琴宝等, 2015; Dong et al, 2017)。与Koppert、BioBee等欧洲专业化公司 相比, 我国在本土熊蜂的人工繁育方面仍存在繁殖 效率较低、生产成本较高、生产过程不稳定等诸多 问题。目前, 本土熊蜂繁育水平还不能满足作物规 模化传粉的需要，其繁育技术仍有待进一步完善。

\section{2 传粉利用}

熊蜂因具有个体大、浑身线毛、趋光性弱、耐 低温、适应低光照和声震传粉等特性而成为设施作 物理想的传粉者(安建东等, 1999)。熊蜂是继蜜蜂之 后人工饲养量最多的传粉昆虫, 全世界每年有 100 万群以上的熊蜂为农作物传粉, 其中 $95 \%$ 以上用于 设施番茄传粉, 面积超过 4 万ha, 年产值超过 120 亿 欧元(Velthuis \& van Doorn, 2006)。熊蜂传粉在设施 农业生产中的作用巨大。

中国是全球设施园艺第一大国, 目前, 设施蔬 菜面积超过 330 多万ha, 产量2.67亿吨, 约占蔬菜总 产量的34\% (张震和刘学瑜, 2015)。中国设施蔬菜中, 茄果类所占比重最大, 但是, 大部分茄果类使用喷 施植物生长调节剂的方法促进坐果, 俗称激素喷 花。与激素喷花相比, 熊蜂传粉不仅能够促进坐果、 提高产量、改善果实品质、节约劳动力、缩短果实 发育历期、避免激素残留, 而且经熊蜂传粉的果实 形状周正, 优质果率高, 产品附加值提高(安建东等, 2004)。随着我国熊蜂人工繁育技术的突破, 本土熊 蜂为设施草莓、番茄、桃、杏等传粉取得了良好效 果(李继莲等, 2006; 彭文君等, 2007; 刘新宇等, 2008; Zhang et al, 2015)。在温室内, 本土熊蜂的传 粉效果优于意大利蜜蜂(Apis mellifera), 与进口的 欧洲地熊蜂相当, 说明本土熊蜂可以替代蜜蜂或者 进口熊蜂为设施作物传粉(陈文锋等, 2011; 董捷等, 2011; 赵亚周等, 2011; 周志勇等, 2015)。如果熊蜂 等传粉昆虫在设施农业中得以很好的应用, 将会大 大提升我国设施蔬果的品质和经济价值。我国设施 作物种类繁多, 将来可进一步挖掘我国丰富的熊蜂 资源, 针对不同作物筛选出最佳的传粉蜂种, 以充分 发挥熊蜂传粉的优良特性，更好地服务于农业生产。

\section{熊蜂保护策略}

熊蜂不仅是设施作物的重要传粉昆虫, 更是众
多野生植物特别是高山植物、高原植物以及一些濒 危植物的重要传粉者(王红和李德铢, 1998; Sun et al, 2003; He \& Liu, 2004; 蒙艳华等, 2007)。据报道，华 北山区77种熊蜂传粉的植物涉及49科339种(An et al, 2014), 云南南瓜农田生态系统中蜜蜂和熊蜂是最 主要的传粉昆虫(谢正华等, 2017), 说明熊蜂传粉在 维持自然和农业生态系统平衡中发挥着十分重要 的作用。但是近几十年来, 全球多个地区出现熊蜂 多样性下降或一些物种面临濒危甚至灭绝的报道 (Potts et al, 2010; Cameron et al, 2011; Colla et al, 2012)。传粉昆虫多样性下降会对自然生态系统和人 类食物安全产生巨大威胁, 为此, 英国(The National Pollinator Strategy: For Bees and Other Pollinators in England, 2014)、美国 (National Strategy to Promote the Health of Honeybees and Other Pollinators, 2015)、 法国(France, Terre de Pollinisateurs, 2015)等发达国 家相继出台了保护传粉昆虫的国家战略规划。中国 熊蜂资源也面临类似的问题，植被的破坏致使云南 澜沧江流域某些熊蜂物种消失、某些物种数量减少 (杨大荣，1999); 过度放牧导致青藏高原东部地区 熊蜂多样性下降(Xie et al, 2008)。作为全球熊蜂资 源最丰富的国家，中国也亟需出台保护熊蜂等传粉 昆虫的国家战略规划。根据熊蜂生存必不可少的基 本条件和影响传粉昆虫多样性下降的因素(Goulson et al, 2008, 2015; Dicks et al, 2016), 熊蜂保护策略 应从以下几个方面开展。

\section{1 保护栖息生境}

生境质量直接影响熊蜂的种群数量。随着人类 活动对自然环境的改变, 致使熊蜂的生境呈现碎片 化, 严重降低了熊蜂的多样性水平。因此, 保护、 修复自然生境以及半自然生境, 提高植物多样性, 为熊蜂提供良好的营巢环境和越冬场所, 对于保护 熊蜂尤为重要(Cameron et al, 2011)。熊蜂喜欢的栖 息环境主要包括野花丰富的草地牧场、原野、灌从、 沟渠、充满杂草的荒野等，人工巢穴、石头堆、废 弃的老鼠洞、干草堆等也是熊蜂经常营巢的场所, 应主动管理、保护和建立这样的栖息环境 (McFrederick \& LeBuhn, 2006)。此外，应根据熊蜂 在我国的分布特征，有针对性地建立一些保护区， 例如在全球熊蜂物种资源最丰富的青藏高原东部 边缘-西秦岭山地建立熊蜂多样性核心保护区，以 保护我国十分丰富的熊蜂物种资源; 在华北地区建 
立火红熊蜂自然保护区, 在华南地区建立双色熊蜂 (Bombus bicoloratus)、黑足熊蜂(B. atripes)自然保护 区, 在青藏高原地区建立凸污熊蜂、华丽熊蜂( $B$. superbus)自然保护区，以保护我国特有种或者稀有 种熊蜂资源。

\section{2 保护食物资源}

熊蜂以花蜜和花粉为食, 在活动周期内, 需要 足够的开花植物为其生存繁衍提供充足的食物资 源(Goulson et al, 2010)。因此，保护自然生境和半自 然生境的植物多样性尤为重要。在农业生产中, 应 尽量避免单一作物大面积种植, 倡导不同作物混合 种植模式, 以延长当地作物的开花期; 同时, 在农 田周边留出非作物生境带(margin), 搭配种植花期 不同的野生植物, 提高植物多样性, 为熊蜂增加食 物来源。不同熊蜂的吻长不一样, 其访花行为也存 在较大差异, 长吻型蜂种偏爱采集长花冠植物, 而 短吻型蜂种适应访问短花冠植物。从保护熊蜂的角 度, 应该种植不同花冠长度的植物以供不同吻长的 熊蜂取食(谢正华和唐亚, 2008; Williams \& Osborne, 2009)。另外，还应根据熊蜂与当地植物协同进化的 原理, 参照本地植物资源进行蜜源植物的补充种植 (Fussell \& Corbet, 1992)。在高山牧场或者草原，应 禁止过度放牧, 以防花卉多样性降低, 导致熊蜂的 食物资源减少(Carvell, 2002; Kosior et al, 2007; Xie et al, 2008)。

\section{3 严防外来物种入侵}

外来物种通常会给当地生物生存带来威胁。随 着全球设施农业的发展, 欧洲地熊蜂被推广至世界 各地，为当地作物提供传粉服务的同时，也在澳大 利亚、日本、阿根廷和智利等国造成了入侵现象 (Hingston et al, 2006; Inoue et al, 2008; Dafni et al, 2010; Schmid-Hempel et al, 2014)。在日本, 欧洲地 熊蜂不仅和当地熊蜂竞争食物资源和营巢场所, 还 和小峰熊蜂(Bombus hypocrita) 竞争交尾, 造成生殖 干扰, 导致小峰熊蜂种群数量下降, 打破了当地植 物的传粉平衡(Kenta et al, 2007; Kanbe et al, 2008)。 欧洲地熊蜂还可能携带新的病虫害, 对当地熊蜂资 源产生严重威胁(Schmid-Hempel et al, 2014)。鉴于 欧洲地熊蜂具有较高的入侵风险, 美国、加拿大、 日本、智利等国已禁止进口该种熊蜂, 转向研究本 土熊蜂资源的利用。不仅如此, 美国还明确规定, 东海岸的熊蜂物种不能转运到西海岸为作物传粉,
以保护当地生态系统不受外来物种干扰。中国是全 球熊蜂资源最丰富的国家，外来熊蜂一旦入侵，对 我国本土熊蜂资源和生态系统造成的危害可能更 大。已有研究表明, 欧洲地熊蜂和我国一些熊蜂种 的雄蜂头部分泌物相似性较高, 在人工条件下可以 和兰州熊蜂杂交, 在自然生境下可能会干扰我国本 土熊蜂的正常繁衍(袁晓龙等, 2018)。所以，我国应 防患于未然, 尽量避免外来熊蜂物种的引入, 加强 管理, 严防生物入侵。

\section{4 减少农药使用}

20世纪以来，农药在农林牧业有害生物防治和 作物增产方面发挥了重要作用，但同时农药的不合 理应用也给生态环境造成了巨大危害(Goulson, 2013)。杀虫剂是引起熊蜂等传粉昆虫多样性下降的 重要因素之一(Goulson et al, 2015)。室内实验表明, 欧洲地熊蜂工蜂取食被吡虫啉污染的食物后, 其产 卵能力明显下降(Laycock et al, 2012)。一旦生境被 噻虫嗪污染，早春时节地熊蜂蜂王的产卵率会显著 下降26\%, 严重影响蜂群的建立(Baron et al, 2017)。 长期暴露在新烟碱类和拟除虫菊酯类杀虫剂的环 境中, 工蜂的采集能力和个体发育均会受到严重影 响, 最终引起工蜂死亡率上升、群势下降, 严重影 响熊蜂的传粉服务能力(Gill et al, 2012)。派人，我们 需要探索环境友好型的农业发展模式, 即在保障食 物安全的前提下，尽可能减少杀虫剂、杀菌剂、除 草剂等农药的使用, 尤其要杜绝滥用。积极倡导植 物病虫害绿色防控技术，推进有机农业发展，切实 保护传粉昆虫资源及其多样性, 维持整个生态系统 的平衡稳定。

\section{5 加强科普宣传}

充分利用报刊、网络、微信、影视等宣传媒介, 加大科普宣传力度, 让更多民众了解熊蜂传粉的生 态价值和经济价值，提高保护意识。不同行业的从 业人员应熟悉相关的保护措施：在林区，应该采用 轮伐、科学间伐、伐种结合等方法, 坚决杜绝砍光、 烧光等高度破坏生态环境的行为; 在牧区，应该采 用轮牧、半场牧等间歇放牧方式，禁止过度放牧; 在农区，要减少杀虫剂的使用，倡导使用生物防治 的方法，禁止在农田间隔带喷施除草剂; 在人们居 住的房前屋后、亭台院落, 种植多样的开花植物, 为熊蜂等传粉昆虫提供食物。通过加强宣传教育, 逐步提高全民对传粉昆虫的保护意识。 


\section{6 加强基础研究}

基础研究可为资源保护和可持续利用提供理 论依据。要保护我国熊蜂资源, 应当加强熊蜂分布 特征、遗传结构、适应性、食物偏好、病虫害、转 基因作物的影响、外来物种的生态安全评估等方面 的基础研究(Potts et al, 2016), 探究影响熊蜂种群分 布的因素、动态变化规律、传粉行为与植物的响应 机制、病虫害危害机制等, 以便及早制定相应的保 护措施。此外, 还应加强熊蜂生物学和人工繁育技 术的研究, 尽早实现本土熊蜂工厂化繁育, 替代进 口蜂种，降低生物入侵风险。

综上，我们基于过去20年对中国熊蜂资源的系 统调查与开发利用研究, 综述了中国熊蜂物种多样 性、人工繁育和传粉利用特点, 提出了保护熊蜂资 源的建议, 以期引起社会广泛关注, 吸引更多科研 工作者、志愿者、相关公益组织参与传粉昆虫的研 究、开发、利用和保护等工作，也期盼我国政府能 够高度重视熊蜂等传粉昆虫资源的保护, 为我国生 态文明建设添砖加瓦。

致谢: 中国科学院动物研究所王淑芳研究员和姚建 老师、英国自然历史博物馆 Paul H. Williams 博士在 熊蜂鉴定中给予热情帮助，中国农业大学彩万志教 授帮助命名熊蜂亚属及部分物种的中文名，全国 23 个协作单位的众多同事在熊蜂资源野外调查中给 予大力支持，在此一并表示感谢!

\section{参考文献}

An JD, Huang JX, Shao YQ, Zhang SW, Wang B, Liu XY, Wu J, Williams PH (2014) The bumblebees of North China (Apidae, Bombus Latreille). Zootaxa, 3830, 1-89.

An JD, Huang JX, Williams PH, Wu J, Zhou BF (2010) Species diversity and colony characteristics of bumblebees in the Hebei region of North China. Chinese Journal of Applied Ecology, 21, 1542-1550. (in Chinese with English abstract) [安建东, 黄家兴, Paul H. Williams, 吴杰, 周冰峰 (2010) 河北地区熊蜂物种多样性与蜂群繁育特性. 应用 生态学报, 21, 1542-1550.]

An JD, Peng WJ, Liang SK (1999) Biological characteristics of bumblebees and its potential using as pollinators. Journal of Bee, (9), 3-5. (in Chinese) [安建东, 彭文君, 梁诗鬼 (1999) 熊蜂的生物学特性及其授粉应用前景. 蜜蜂杂志, (9), 3-5.]

An JD, Tong YM, Guo ZB, Peng WJ, Wu J, Sun YS, Li NG (2004) A study on Bombus terrestris pollination to green- house eggplant. Apiculture of China, 55, 7-8. (in Chinese with English abstract) [安建东, 童越敏, 国占宝, 彭文君, 吴杰, 孙永深, 李乃光 (2004) 熊蜂为温室茄子授粉试 验. 中国养蜂, 55, 7-8.]

An JD, Williams PH, Zhou BF, Miao ZY, Qi WZ (2011) The bumblebees of Gansu, Northwest China (Hymenoptera, Apidae). Zootaxa, 2865, 1-36.

An JD, Wu J, Peng WJ, Tong YM, Guo ZB, Li JL (2007) Foraging behavior and pollination ecology of Bombus lucorum L. and Apis mellifera L. in greenhouse peach garden. Chinese Journal of Applied Ecology, 18(5), 5-9. (in Chinese with English abstract) [安建东, 吴杰, 彭文君, 童越敏, 国 占宝, 李继莲 (2007) 明亮熊蜂和意大利蜜蜂在温室桃 园的访花行为和传粉生态学比较. 应用生态学报, 18(5), 5-9.]

An JD, Yao J, Huang JX, Shao YQ, Wu J, Li JL, Shi HY (2008) Bombus Fauna (Hymenoptera, Apidae) in Shanxi, China. Acta Zootaxonomica Sinica, 33, 80-88. (in Chinese with English abstract) [安建东, 姚建, 黄家兴, 邵有全, 吴 杰, 李继莲, 施海燕 (2008) 山西省熊蜂属区系调查(膜 翅目, 蜜蜂科). 动物分类学报, 33, 80-88.]

Baron GL, Jansen V, Brown M, Raine NE (2017) Pesticide reduces bumblebee colony initiation and increases probability of population extinction. Nature Ecology \& Evolution, 1, 1308-1316.

Bischoff H (1936) Schwedisch-chinesische wissenschaftliche Expedition nach den nordwestlichen Provinzen Chinas, unter Leitung von Dr. Sven Hedin und Prof. Sü Ping-chang. Insekten gesammelt vom schwedischen Arzt der Expedition Dr. David Hummel 1927-1930. 56. Hymenoptera. 10. Bombinae. Arkiv för Zoologi, 27A, 1-27. (in German)

Cameron SA, Hines HM, Williams PH (2007) A comprehensive phylogeny of the bumble bees (Bombus). Biological Journal of the Linnean Society, 91, 161-188.

Cameron SA, Lozier JD, Strange JP, Koch JB, Cordes N, Solter LF, Griswold TL (2011) Patterns of widespread decline in North American bumble bees. Proceedings of the National Academy of Sciences, USA, 108, 662-667.

Carvell C (2002) Habitat use and conservation of bumblebees (Bombus spp.) under different grassland management regimes. Biological Conservation, 103, 33-49.

Chen WF, An JD, Dong J, Ding KF, Gao S (2011) Flowervisiting behavior and pollination ecology of different bee species on greenhouse strawberry. Chinese Journal of Ecology, 30, 290-296. (in Chinese with English abstract) [陈文 锋, 安建东, 董捷, 丁克法, 高山 (2011) 不同蜂在温室 草莓园的访花行为和传粉生态学比较. 生态学杂志, 30, 290-296.]

Colla SR, Gadallah F, Richardson L, Wagner D, Gall L (2012) Assessing declines of North American bumble bees (Bombus spp.) using museum specimens. Biodiversity and Conservation, 21, 3585-3595.

Dafni A, Kevan P, Gross CL, Goka K (2010) Bombus terrestris, 
pollinator, invasive and pest: An assessment of problems associated with its widespread introductions for commercial purposes. Applied Entomology and Zoology, 45, 101-113.

Dicks LV, Viana B, Bommarco R, Brosi B, Arizmendi MD, Cunningham SA, Galetto L, Hill R, Lopes AV, Pires C, Taki H, Potts SG (2016) Ten policies for pollinators. Science, 354, 975-976.

Dong J, An JD, Huang JX, Zhou ZY, Zhao YZ, Xing YH (2011) Effects of pollination by different bees on peach fruit development and quality under greenhouse conditions. Chinese Journal of Eco-Agriculture, 19, 836-842. (in Chinese with English abstract) [董捷, 安建东, 黄家兴, 周志勇, 赵 亚周, 邢艳红 (2011) 不同蜂传粉对设施桃果实生长发 育和品质的影响. 中国生态农业学报, 19, 836-842.]

Dong J, Han L, Wang Y, Huang JX, Wu J (2017) Transcript expression bias of phosphatidylethanolamine binding protein gene in bumblebee, Bombus lantschouensis (Hymenoptera: Apidae). Gene, 627, 290-297.

Fussell M, Corbet SA (1992) Flower usage by bumble-bees: A basis for forage plant management. Journal of Applied Ecology, 29, 451-465.

Gai QB, Zhou ZY, Zhang H, Huang JX, An JD (2015) Optimizing supplementary pollen mixtures for bumblebee Bombus terrestris colonies based on colony reproductive variables. Chinese Journal of Applied Entomology, 52, 333-342. (in Chinese with English abstract) [盖琴宝, 周志 勇, 张红, 黄家兴, 安建东 (2015) 地熊蜂蜂群发育性状 评价及其饲料花粉配比优化. 应用昆虫学报, 52, 333-342.]

Gill RJ, Ramosrodriguez O, Raine NE (2012) Combined pesticide exposure severely affects individual- and colony-level traits in bees. Nature, 491, 105-108.

Goulson D (2013) Review: An overview of the environmental risks posed by neonicotinoid insecticides. Journal of Applied Ecology, 50, 977-987.

Goulson D, Lepais O, O’Connor S, Osborne JL, Sanderson RA, Cussans J, Goffe L, Darvill B (2010) Effects of land use at a landscape scale on bumblebee nest density and survival. Journal of Applied Ecology, 47, 1207-1215.

Goulson D, Lye GC, Darvill B (2008) Decline and conservation of bumble bees. Annual Review of Entomology, 53, 191-208.

Goulson D, Nicholls E, Botías C, Rotheray EL (2015) Bee declines driven by combined stress from parasites, pesticides, and lack of flowers. Science, 347, 1255957.

He Y, Liu J (2004) Pollination ecology of Gentiana straminea Maxim. (Gentianaceae), an alpine perennial in the Qinghai-Tibet Plateau. Acta Ecologica Sinica, 24, 215-220.

Heinrich B (1979) Bumblebee Economics. Harvard University Press, Cambridge (Massachusetts).

Hingston AB, Herrmann W, Jordan GJ (2006) Reproductive success of a colony of the introduced bumblebee Bombus terrestris (L.) (Hymenoptera: Apidae) in a Tasmanian Na- tional Park. Australian Journal of Entomology, 45, 137-141.

Huang JX, An JD, Wu J, Williams PH (2015a) Extreme food-plant specialisation in Megabombus bumblebees as a product of long tongues combined with short nesting seasons. PLoS ONE, 10, e132358.

Huang JX, Wu J, An JD, Williams PH (2015b) Newly discovered colour-pattern polymorphism of Bombus koreanus females (Hymenoptera: Apidae) demonstrated by DNA barcoding. Apidologie, 46, 250-261.

Inoue MN, Yokoyama J, Washitani I (2008) Displacement of Japanese native bumblebees by the recently introduced Bombus terrestris (L.) (Hymenoptera: Apidae). Journal of Insect Conservation, 12, 135-146.

Kanbe Y, Okada I, Yoneda M, Goka K, Tsuchida K (2008) Interspecific mating of the introduced bumblebee Bombus terrestris and the native Japanese bumblebee Bombus hypocrita sapporoensis results in inviable hybrids. Naturwissenschaften, 95, 1003-1008.

Kenta T, Inari N, Nagamitsu T, Goka K, Hiura T (2007) Commercialized European bumblebee can cause pollination disturbance: An experiment on seven native plant species in Japan. Biological Conservation, 134, 298-309.

Kosior A, Celary W, Olejniczak P, Fijal J, Król W, Solarz W, Plonka P (2007) The decline of the bumble bees and cuckoo bees (Hymenoptera: Apidae: Bombini) of Western and Central Europe. Oryx, 41, 79-88.

Laycock I, Lenthall KM, Barratt AT, Cresswell JE (2012) Effects of imidacloprid, a neonicotinoid pesticide, on reproduction in worker bumble bees (Bombus terrestris). Ecotoxicology, 21, 1937-1945.

Li JL, Peng WJ, Wu J, An JD, Guo ZB, Tong YM, Huang JX (2006) Strawberry pollination by Bombus lucorum and Apis mellifera in greenhouses. Acta Entomologica Sinica, 49, 342-348. (in Chinese with English abstract) [李继莲, 彭文 君, 吴杰, 安建东, 国占宝, 童越敏, 黄家兴 (2006) 明 亮熊蜂和意大利蜜蜂为温室草莓的授粉行为比较观察. 昆虫学报, 49, 342-348.]

Liang SK, Wu J, Peng WJ, Zhang GL, Wang JC, An JD (1999) Biological observation of bumblebees and its rearing in captivity. Apiculture of China, 50, 17-18. (in Chinese) [梁诗魁, 吴杰, 彭文君, 张国良, 王加聪, 安建东 (1999) 熊蜂的 生物学观察及室内繁育. 中国养蜂, 50, 17-18.]

Liu P, Huang JX, An JD, He SY, Wu J (2014) Molecular identification and distribution characteristics of the bumblebee Bombus lucorum complex in China. Acta Entomologica Sinica, 57, 235-243. (in Chinese with English abstract) [刘 苹, 黄家兴, 安建东, 和绍禹, 吴杰 (2014) 中国明亮熊 蜂复合种的分子鉴定及分布特性. 昆虫学报, 57, 235-243.]

Liu XY, Gao CD, Zhang JG, Liu HY, Tian HY (2008) Tomato pollinated by Bombus patagiatus in Northern Shaanxi Province. Northwest Horticulture, (2), 50-51. (in Chinese) [刘新 宇, 高崇东, 张建国, 刘汉玉, 田慧宇 (2008) 温室番茄 
陕北密林熊蜂授粉试验. 西北园艺, (2), 50-51.]

McFrederick QS, LeBuhn G (2006) Are urban parks refuges for bumble bees Bombus spp. (Hymenoptera: Apidae)? Biological Conservation, 129, 372-382.

Meng YH, Xu HL, Chen X, Cai QN (2007) Pollination efficiency of the main bee pollinators of Hedysarum laeve, a legume in $\mathrm{Mu}$ Us Sandland, Inner Mongolia. Biodiversity Science, 15, 633-638. (in Chinese with English abstract) [蒙 艳华, 徐环李, 陈轩, 蔡青年 (2007) 塔落岩黄芪主要传 粉蜂的传粉效率研究. 生物多样性, 15, 633-638.]

Панфилов ДВ (1957) О географическом распространении шмелей (Bombus) в Китае. Acta Geographica Sinica, 23, 221-239. (in Chinese and Russian) [潘菲洛夫 (1957) 中国 熊蜂(Bombus)的分布. 地理学报, 23, 221-239.]

Peng WJ, Wu J, An JD, Xing YH (2007) Comparative studies on pollination biology of Bombus lucorum and Apis mellifera ligustica in Katy apricot greenhouse. Journal of Fujian Agriculture and Forestry University (Natural Science Edition), 36, 139-142. (in Chinese with English abstract) [彭文 君, 吴杰, 安建东, 邢艳红 (2007) 温室凯特杏园明亮熊 蜂和意大利蜜蜂的传粉生物学比较. 福建农林大学学报 (自然科学版), 36, 139-142.]

Potts SG, Biesmeijer JC, Kremen C, Neumann P, Schweiger O, Kunin WE (2010) Global pollinator declines: Trends, impacts and drivers. Trends in Ecology \& Evolution, 25, 345-353.

Potts SG, Imperatriz-Fonseca V, Ngo HT, Aizen MA, Biesmeijer JC, Breeze TD, Dicks LV, Garibaldi LA, Hill R, Settele J, Vanbergen AJ (2016) Safeguarding pollinators and their values to human well-being. Nature, 540, 220-229.

Schmid-Hempel R, Eckhardt M, Goulson D, Heinzmann D, Lange C, Plischuk S, Ruz EL, Salathe R, Scriven JJ, Schmid-Hempel P (2014) The invasion of southern South America by imported bumblebees and associated parasites. Journal of Animal Ecology, 83, 823-837.

Starr CK (1992) The bumble bees (Hymenoptera: Apidae) of Taiwan. Bulletin of National Museum of Natural Science, 3, 139-157.

Sun HQ, Luo YB, Ge S (2003) A preliminary study on pollination biology of an endangered orchid, Changnienia amoena, in Shennongjia. Acta Botanica Sinica, 45, 1019-1023.

Velthuis H, van Doorn A (2006) A century of advances in bumblebee domestication and the economic and environmental aspects of its commercialization for pollination. Apidologie, 37, 421-451.

Wang H, Li DZ (1998) A preliminary study of pollination biology of Pedicularis (Scrophulariaceae) in northwest Yunnan, China. Acta Botanica Sinica, 40, 21-27. (in Chinese with English abstract) [王红, 李德铢 (1998) 滇西北马先 蒿属传粉生物学的初步研究. 植物学报, 40, 21-27.]

Wang SF (1985) Apidae-Bombus. In: Organisms of the Tuomuerfeng Region of Tianshan (ed. Mountaineering Scientific Expedition Team of the Chinese Academy of Sci- ences), pp. 160-165. Xinjiang People’s Publishing House, Urumqi. (in Chinese) [王淑芳 (1985) 蜜蜂科: 熊蜂属. 见: 天山托木尔峰地区的生物 (中国科学院登山科学考 察队主编), 160-165页. 新疆人民出版社, 乌鲁木齐.]

Wang SF (1982) Hymenoptera: Apidae-Bombus. In: Insects of Xizang (Vol. 2) (ed. Qinghai-Tibet Plateau Comprehensive Scientific Expedition Team of the Chinese Academy of Sciences), pp. 427-447. Science Press, Beijing. (in Chinese) [王淑芳 (1982) 膜翅目: 蜜蜂科——熊蜂属. 见: 西藏昆 虫(第2册) (中国科学院青藏高原综合科学考察队主编), 427-447页. 科学出版社, 北京.]

Williams PH (1996) Mapping variations in the strength and breadth of biogeographic transition zones using species turnover. Proceedings of the Royal Society of London B-Biological Sciences, 263, 579-588.

Williams PH (1998) An annotated checklist of bumble bees with an analysis of patterns of description (Hymenoptera: Apidae, Bombini). Bulletin of the Natural History Museum Entomology, 67, 79-152.

Williams PH, An JD, Brown MJF, Carolan JC, Goulson D, Huang JX, Ito M (2012a) Cryptic bumblebee species: Consequences for conservation and the trade in greenhouse pollinators. PLoS ONE, 7, e32992.

Williams PH, An JD, Huang JX (2011) The bumblebees of the subgenus Subterraneobombus: Integrating evidence from morphology and DNA barcodes (Hymenoptera, Apidae, Bombus). Zoological Journal of the Linnean Society, 163, 813-862.

Williams PH, An JD, Huang JX, Yao J (2010) BBCI: A new initiative to document Chinese bumble bees for pollination research. Journal of Apicultural Research and Bee World, 49, 221-222.

Williams PH, Brown MJF, Carolan JC, An JD, Goulson D, Aytekin AM, Best LR, Byvaltsev AM, Cederberg B, Dawson R, Huang JX, Ito M, Monfared A, Raina RH, Schmid-Hempel P, Sheffield CS, Šima P, Xie ZH (2012b) Unveiling cryptic species of the bumblebee subgenus Bombus s. str. worldwide with COI barcodes (Hymenoptera: Apidae). Systematics and Biodiversity, 10, 1-36.

Williams PH, Bystriakova N, Huang JX, Miao ZY, An JD (2015) Bumblebees, climate and glaciers across the Tibetan Plateau (Apidae: Bombus Latreille). Systematics and Biodiversity, 13, 164-181.

Williams PH, Cameron SA, Hines HM, Cederberg B, Rasmont $P$ (2008) A simplified subgeneric classification of the bumblebees (genus Bombus). Apidologie, 39, 46-74.

Williams PH, Huang JX, An JD (2017) Bear wasps of the Middle Kingdom: A decade of discovering China's bumblebees. Antenna, 41, 21-24.

Williams PH, Huang JX, Rasmont P, An JD (2016) Earlydiverging bumblebees from across the roof of the world: The high-mountain subgenus Mendacibombus revised from species' gene coalescents and morphology (Hymenoptera, 
Apidae). Zootaxa, 4204, 1-72.

Williams PH, Osborne JL (2009) Bumblebee vulnerability and conservation world-wide. Apidologie, 40, 367-387.

Williams PH, Tang Y, Yao J, Cameron S (2009) The bumblebees of Sichuan (Hymenoptera: Apidae, Bombini). Systematics and Biodiversity, 7, 101-187.

Williams PH, Thorp RW, Richardson LL, Colla SR (2014) Bumble Bees of North America. Princeton University Press, New Jersey.

Wu YR, He W, Wang SF (1988) Bees of Yunnan. Yunnan Science and Technology Press, Kunming. [吴燕如, 何琬, 王淑芳 (1988) 云南蜜蜂志. 云南科技出版社, 昆明.]

Xie ZH (2008) The Effect of Anthropenic Disturbance on Diversity of Bumblebees (Bombus spp.) in Sichuan, China. $\mathrm{PhD}$ dissertation, Sichuan University, Chengdu. (in Chinese with English abstract) [谢正华 (2008) 四川熊蜂多样性与 人类活动关系研究. 博士学位论文, 四川大学, 成都.]

Xie ZH, Tang Y (2008) A study on food plant preference of bumblebees from Sichuan, China. Journal of Mountain Science, 26, 605-611. (in Chinese with English abstract) [谢正 华, 唐亚 (2008) 四川熊蜂蜜粉源植物选择偏好. 山地学 报, 26, 605-611.]

Xie ZH, Teichroew J, An JD (2017) Responses of summer squash pollinator density to habitat loss in Southeast Yunnan. Chinese Journal of Eco-Agriculture, 25, 337-344. (in Chinese with English abstract) [谢正华, Jonathan Teichroew, 安建东 (2017) 滇东南南瓜传粉昆虫密度对 生境丧失的差异性响应.中国生态农业学报, 25, 337-344.]

Xie ZH, Williams PH, Tang Y (2008) The effect of grazing on bumblebees in the high rangelands of the eastern Tibetan Plateau of Sichuan. Journal of Insect Conservation, 12, 695-703

Yang DR (1999) The status of species diversity and conservation strategy of bumble bees, a pollination insect in Lancang River Basin of Yunnan, China. Chinese Biodiversity, 7, 11-15. (in Chinese with English abstract) [杨大荣 (1999) 云南澜沧江流域传粉昆虫——熊蜂多样性现状与保护对 策. 生物多样性, 7, 11-15.]

Yao J, Luo CY (1997) Hymenoptera: Apidae: Bombini. In: Insects of the Three Gorge Reservoir Area of Yangtze River (ed. Yang XK), pp. 1686-1696. Chongqing Publishing House, Chongqing. (in Chinese) [姚建, 罗春勇 (1997) 膜 翅目: 蜜蜂科: 熊蜂族. 见: 长江三峡库区昆虫 (杨星科 主编), 1686-1696页. 重庆出版社, 重庆.]

Yao J, Wang SF (2005) Hymenoptera: Apidae: Bombini. In: Insect Fauna of Middle-West Qinling Range and South
Mountains of Gansu Province (ed. Yang XK), pp. 890-896. Science Press, Beijing. (in Chinese) [姚建，王淑芳 (2005) 膜翅目: 蜜蜂科——熊蜂族. 见: 秦岭西段及甘南地区昆 虫 (杨星科主编), 890-896页. 科学出版社, 北京.]

Yu WJ, Mao HX, Wang DS, Zhao JY, Yuan YD (2003) A preliminary investigation on bumblebees in the Tianmushan Mountains of Zhejiang Province. Acta Agriculturae Shanghai, 19, 70-72. (in Chinese with English abstract) [於文俊, 茅洪新, 王冬生, 赵京音, 袁永达 (2003) 浙江天目山熊 蜂的初步调查. 上海农业学报, 19, 70-72.]

Yuan XL, Naeem M, Zhang H, Liang C, Huang JX, An JD (2018) Evaluation of reproductive disturbance to Chinese bumblebees by the European bumblebee, Bombus terrestris (Hymenoptera: Apidae). Acta Entomologica Sinica, 61, 348-359. (in Chinese with English abstract) [袁晓龙, M. Naeem, 张红, 梁铖, 黄家兴, 安建东 (2018) 欧洲地熊 蜂对我国本土熊蜂的生殖干扰评估. 昆虫学报, 61, 348-359.]

Zhang H, Huang JX, Williams PH, Vaissière BE, Zhou ZY, Gai QB, Dong J, An JD (2015) Managed bumblebees outperform honeybees in increasing peach fruit set in China: Different limiting processes with different pollinators. PLoS ONE, 10, e121143.

Zhang Z, Liu XY (2015) Development status and countermeasures of protected agriculture in China. Issues in Agricultural Economy, (5), 64-70. (in Chinese) [张震, 刘学瑜 (2015) 我国设施农业发展现状与对策. 农业经济问题, (5), 64-70.]

Zhao YZ, An JD, Zhou ZY, Dong J, Xing YH, Qin JJ (2011) Pollination behavior of Apis mellifera ligustica and Bombus hypocrita (Hymenoptera, Apidae) and the influencing factors in peach greenhouse. Acta Entomologica Sinica, 54, 89-96. (in Chinese with English abstract) [赵亚周, 安建东, 周志勇, 董捷, 邢艳红, 秦建军 (2011) 意大利蜜蜂和小 峰熊蜂在温室桃园的传粉行为及其影响因素. 昆虫学报, 54, 89-96.]

Zhou ZY, Zhang H, Liang C, Zou Y, Dong J, Yuan XL, Huang JX, An JD (2015) Foraging preference of the honeybee Apis mellifera and the bumblebee Bombus lantschouensis (Hymenoptera: Apidae) in peach greenhouse. Acta Entomologica Sinica, 58, 1315-1321. (in Chinese with English abstract) [周志勇, 张红, 梁铖, 邹宇, 董捷, 袁晓龙, 黄 家兴, 安建东 (2015) 西方蜜蜂和兰州熊蜂在设施桃园 的访花偏好性比较. 昆虫学报, 58, 1315-1321.]

(责任编委: 黄双全 责任编辑: 间文杰) 